University of Wisconsin Milwaukee

UWM Digital Commons

Changes in the Extent and Distribution of Urban Land Cover in the Democratic People's Republic of Korea (North Korea) Between 1987 and 2010

Sangjun Kang

Jinmu Choi

Hyejin Yoon

Woonsup Choi

Follow this and additional works at: https://dc.uwm.edu/geog_facart

Part of the Geography Commons

This Article is brought to you for free and open access by UWM Digital Commons. It has been accepted for inclusion in Geography Faculty Articles by an authorized administrator of UWM Digital Commons. For more information, please contact scholarlycommunicationteam-group@uwm.edu. 


\title{
FULL TITLE: CHANGES IN THE EXTENT AND DISTRIBUTION OF URBAN LAND COVER IN THE DEMOCRATIC PEOPLE'S REPUBLIC OF KOREA (NORTH KOREA) BETWEEN 1987 AND
} 2010

\section{SHORT TITLE: URBAN LAND COVER IN NORTH KOREA BETWEEN 1987 AND 2010}

\author{
AUTHORS \\ Sangjun Kang \\ Dept. of Regional Development, Gangneung-Wonju National University \\ kangsangjun@gmail.com \\ Gangneung-si, Gangwon-do, Republic of Korea
}

Jinmu Choi (corresponding author)

Dept. of Geography, Kyung Hee University

cjm89@khu.ac.kr

Dongdaemun-gu, Seoul, Republic of Korea

\author{
Hyejin Yoon \\ Dept. of Geography, University of Wisconsin-Milwaukee \\ yoon3@uwm.edu \\ Milwaukee, Wisconsin, United States
}

\author{
Woonsup Choi \\ Dept. of Geography, University of Wisconsin-Milwaukee \\ choiw@uwm.edu
}

Milwaukee, Wisconsin, United States

This is an Accepted Manuscript of an article published by Wiley in Land Degradation \& Development in volume 30 in 2019, available online: https://onlinelibrary.wiley.com/doi/10.1002/ldr.3396 


\section{Abstract}

4 Largely due to data unavailability, the spatial pattern of urban growth in North Korea has

5 been rarely studied. This study explored urban changes in North Korea and provided their

6 plausible causes. The present study used satellite-based land cover datasets produced by

7 the government of South Korea to examine the extent and distribution of urban land

8 cover in North Korea between the late 1980s (1987-1989) and late 2000s (2008-2010) at

9 the municipal level. Urban Expansion Intensity Index (UEII) was calculated for two ten-

10 year intervals and the spatial autocorrelation of UEII values was examined. Major

11 findings from the study are summarized as follows: (1) the capital city Pyongyang's

12 dominance continued without an obvious sign of slowing down; (2) economic

13 development districts do not appear to have much influence on urban land cover changes;

14 and (3) the extent of urban land cover slightly decreased in much of the country between

15 the late 1990s (1997-1999) and late 2000s (2008-2010). The results and discussion in this

16 study suggest internal migration and stagnant economy as probably important causes for

17 the phenomena.

19 Keywords: North Korea, land cover, urban growth, urban expansion intensity index 


\section{Introduction}

Shortly after the end of the Second World War in 1945, vastly different politicaleconomic governments were established in North and South Koreas, respectively. A communist government was established in North Korea (officially known as the Democratic People's Republic of Korea), and it maintained robust economic growth and higher GDP per capita than South Korea (officially known as the Republic of Korea) through the 1960s but stagnated thereafter (Jo \& Adler, 2002; Statistics Korea, 1995). The communist government lead to formation of a distinct spatial structure from that of South Korea, which adopted a capitalist development strategy (Jo \& Adler, 2002). The formation of spatial structure in North Korea was strongly influenced by the socialist ideology, political and military considerations, and urban planning policies (Lim, 2009). As a result, city rankings by population in North Korea changed significantly over time since the establishment of the communist government (Jo \& Adler, 2002; Jo, 2013). Pyongyang ${ }^{1}$, the capital city, remained to be the largest city, but others fell in ranking and new ones rose (Jo \& Adler, 2002). However, North Korea does not regularly produce census data, of which reliability is questionable at any rate (Lee, 2011). Therefore, research into changes in spatial structure in North Korea remains challenging.

Growth of cities in North Korea inevitably resulted in land use/cover changes (e.g., conversion of croplands to residential lands), but due to the lack of data and accessibility, it has not been well studied. A few studies (Engler et al., 2014; Choi et al., 2017; Kang \& Choi, 2014; Zheng et al., 1997) on land cover changes in North Korea focused on deforestation using satellite remote sensing-based data. Satellite remote sensing images contain digital numbers that reflect the signal received by the sensor, and the digital numbers are classified into land cover categories. Previous studies on the spatial structure in North Korea focused on the national scale structure (Lim, 2009) or the population of cities (Jo \& Adler, 2002) and did not examine the changes in the extent and distribution of urban land cover. Examining land cover changes is necessary to complement the investigation of spatial structure in North Korea with spatial details. The Ministry of Environment of the Republic of Korea produced high-resolution land cover dataset for the entire Korean Peninsula representing the late 1980s (1987-1989), late 1990s (19971999), and late 2000s (2008-2010). Using the data, this study contributes to deeper understanding of the expansion of urban land cover in North Korea since the late 1980s.

The investigation starts from the late 1980s because of data availability, but the 1980s are also the time when North Korea began to noticeably change its economic policy. The economic degradation that began to occur in the mid-1970s is related to the development of cities in the east- and west-coast regions in the 1980s for enhancing economic productivity (Jo \& Adler, 2002). In 1984, North Korea enacted a law (so-called habyeongbeop) allowing foreign direct investment. In 1991, it designated a region of 621 $\mathrm{km}^{2}$ in the northeast corner as a 'free economy and trade district' and two ice-free port

${ }^{1}$ Place names and other words in the Korean language in this article are transliterated according to the Notification 2000-8 of the Ministry of Culture, Sports and Tourism of the Republic of Korea except for Pyongyang, which is transliterated worldwide as such. 
cities in the district (Rajin and Seonbong) as free trade ports (Lee, 2015). The district was intended to function as hubs for trade, manufacturing, tourism, and banking (North Korea Information Portal a). Being about $100 \mathrm{~km}$ from the Russian city of Vladivostok, it shares the border with both China and Russia. North Korea continued to increase the extent to which it opens its economy to the outside world and loosened grip on the economy in response to the crisis in its state-controlled economy in the 1990s. Private markets were permitted more widely and additional special economic zones were designated (North Korea Information Portal a). We speculate that such socio-economic changes drove land cover changes to some (unknown) extent. This study attempted to examine the changes in the extent and distribution of urban land cover in North Korea. Specifically, this study intended to answer the following questions: (1) What are the spatial characteristics of urban expansion in North Korea between the late 1980s and late 2000s? and (2) How do the characteristics differ between the decade of 1980s-1990s and that of 1990s-2000s? While answering the questions, we examined significant policy and socio-economic changes that could be related to the urban land cover change.

\section{Materials and Methods}

\section{Study area}

The study was conducted for the entire North Korea. The administrative district map of North Korea at the provincial and major city levels is provided in Figure 1. The ten largest cities by population were identified from the 2008 census data (re-cited from Jo (2013)). Pyongyang (the capital) is a province-level city. Pyongyang was the largest city with a population of 3.25 million, followed by Hamheung $(769,000)$ and Cheongjin $(668,000)$. Sariweon, the $10^{\text {th }}$ largest city, had a population of 307,764 . The entire country had a population of about 24 million, and the ratio of urban population was $60.6 \%$ (Statistics Korea, 2011). By comparison, the ratio was more than $80 \%$ in South Korea. Because North Korea frequently changed administrative districts throughout the history, city-level population changes between censuses should be examined with caution (Jo, 2013). For example, Nampo's population was 367,000 in the 2008 census but was 731,000 in the 1993 census. It is believed to be due to redistricting (Jo, 2013).

Many of the ten largest cities are historically large cities (Pyongyang, Hamheung, Cheongjin, Weonsan, Sariweon, and Sineuiju). They had grown into large cities before the establishment of the communist government and maintained steady growth since then (Jo, 2013). Particularly, Hamheung and Cheongjin saw heavy industry develop during the Japanese colonial period (Lim, 2009). Nampo is a satellite city to Pyongyang and heavyindustry-oriented, whereas Dancheon contains significant rural population (30\% of total) (Jo, 2013) and is also heavy-industry-oriented (Lim, 2009).

\section{Data}

The data used for this study consist of three gridded land cover data sets of North Korea, each of which represents land cover conditions in the late 1980s, 1990s, and 2000s, 
respectively. Hereafter, they are referred to as the 1980s, 1990s, and 2000s data sets.

109 Land cover data as digital maps were produced by the Republic of Korea's Ministry of

110 Environment (MoE) (MoE 2016). The 1980s and 1990s data sets were produced from the

111 Landsat TM imagery for 1987-1989 and 1997-1999, respectively. The 2000s data set was

112 produced from the Landsat 7 ETM imagery for 2008-2010 (MoE 2016). Each land cover

113 digital map covers 1509150 at the 1:50,000 scale so that 487 maps were produced to

114 cover the entire North Korea for each term. For the accuracy assessment, MoE derived

115 samples from the center of the 1-min grids of each 1:50,000 digital map (150 9 150) so

116 that 225 samples were checked for each map. As reference data, topographic maps for

117 North Korea $(1: 50,000)$, military base maps $(1: 50,000)$ by the Republic of Korea Army

118 Mapping Agency, forest type maps, and vegetation maps were used. According to the

119 land cover map guideline by $\mathrm{MoE}$ (2013), the land cover data had more than $70 \%$

120

121

122

123

124

125

126

127

128

129

130

131

132

133

134

135

136

137

138

139 accuracy for classification in the North Korean region. The maps have seven land cover classes: water, developed, barren land, grassland, wetland, forest, and agriculture. Further description of the data can be found in previous studies that used the same data set (Choi et al., 2017; Kang \& Choi, 2014).

For the analysis, first, the portion of North Korea was clipped out from the original data sets for the three periods. The land cover data were then pre-processed to extract urban areas. In this study we used the 'developed' class as substitute for urban land cover. According to the Ministry of Environment (2013), the 'developed' class includes built-up areas such as residential, commercial, industrial, and transportation. Three grid maps containing only urban pixels were generated.

\section{Urban Expansion Intensity Index (UEII)}

The urban expansion intensity index (UEII) for a spatial unit can be defined as the average annual proportion of newly increased urban area to its total area. In other words, it indicates how much urban areas increased in spatial unit $i$ with respect to the total size of spatial unit $i$. UEII is calculated using the following equation:

$$
U E I I_{i}=\frac{U L A_{i}^{t_{2}}-U L A_{i}^{t_{1}}}{T L A_{i} \times \Delta t} \times 100
$$

$\Delta t$

144

145

146

147

148

149

150

151
This method has been used to quantify the magnitude of urban sprawl or expansion in multiple studies. For example, Hwang et al. (2011) employed the UEII method to compare the urbanization patterns of suburban municipalities around the City of Seoul, Republic of Korea, and Kang (2016) explored the spatial relations between the urban area expansion and developed area fragmentation in Gangwon Province, Republic of Korea. Lu et al. (2014) employed the UEII method to explore and understand the spatio-temporal features and their trends found in urban land expansion across the different decades in the 
Wuhan region, central China. They found that the spatial expansion pattern of the study area was concentrated and regionally imbalanced across the overall study period.

In this study, we calculated UEII for two time periods: between 1980s and 1990s and between 1990s and 2000s. The spatial unit was municipality (si or gun in Korean) that are fully nested in 10 provinces (do in Korean). We counted 196 municipalities in the administrative boundary map. It should be noted that administrative districts were likely to be different in the 1980s and 1990s. We used the same administrative map for previous decades to maintain consistency. Since we examined changes not in population but in the

\section{Local Moran's I}

Local Moran's $I$ statistic can identify spatial clusters and outliers in spatial data (Anselin, 1995). The value of local Moran's $I$ at each enumeration unit is determined from the values of the attribute of neighboring units (Eq. 2 and 3). Positive values indicate that a unit has a similar attribute value to its neighbors, whereas negative values indicate that the area has both low and high attribute value units. Thus, local Moran's $I$ is an indicator of data homogeneity or diversity. In the result map, each enumeration unit will have $\mathrm{HH}$ (High-High), HL (High-Low), LH (Low-High), or LL (Low-Low) designations if the spatial association is statistically significant (O'Sullivan \& Unwin, 2010). HH means both target and its neighboring units have high UEII values and LL means both target and its neighbors have low UEII values. HL represents that target unit has high UEII and neighbors have low UEII, and LH represents the inverse of HL. Therefore, it allows us to easily identify which part of North Korea experienced high urban expansion. If the local pattern is random, the association is not statistically significant.

$$
I_{i}=\frac{x_{i}-\bar{X}}{s_{i}{ }^{2}} \sum_{j=1, j \neq i}^{n} w_{i, j}\left(x_{j}-\bar{X}\right)
$$

where $x_{i}$ is an attribute for feature $i, \bar{X}$ is the mean of the corresponding attributes, $w_{i, j}$ is the spatial weight between feature $i$ and $j$, and:

$$
S_{i}{ }^{2}=\frac{\sum_{j=1, j \neq i}^{n}\left(x_{j}-\bar{X}\right)^{2}}{n-1}-\bar{X}^{2}
$$

with $n$ equating to the total number of features.

\section{Results}

\section{Urban land cover change}

Increases in urban pixels are clearly visible between the late 1980s data and late 2000s data (Figure 2), particularly in the western inland and eastern coastal regions. The western inland region contains Pyongyang, which has been the most dominant city in the country. As seen in Figure 1, its areal extent is quite large, and it is a province-city 
containing substantial rural areas. Figure 2 suggests that urban expansion occurred fast in the rural area of the province-city, resulting in an increase of $27 \%$ (Table 1). Nampo also gained more than 20\%. Urban pixels increased by more than $300 \%$ in Dancheon on the east coast (Table 1). Other cities on the east coast gained urban pixels substantially, for example Cheongjin 48\% and Weonsan 32\%. Hamheung, which was the second or third most populous city in the country in the last several censuses, gained $13 \%$.

Increases in urban pixels are hard to find in the central inland region. Before the mid1970s, North Korea actively pursued development of cities in the central inland region for regional balance and military considerations (Jo \& Adler, 2002) and to promote trade with China (Hastings, 2016). However, the region had none of the top ten cities by population. The most populated city in the region is Ganggye $(252,000)$, ranked $14^{\text {th }}$ in the latest census. Such government-led development appears to have stalled on the land cover dataset, and some urban pixels are visible only for the 1980s, indicating some urban land cover converted to non-urban since the 1990s. On the other hand, the small change along the border with South Korea is in part due to the concentration of development around Pyongyang (Jo \& Adler, 2002). Even though the changes are small along the entire border, the urban area in Gaeseong increased from 1987 to 2010. In particular, Kaesong (Gaeseong) Industrial Region broke ground in 2003 and its phase 1 was completed in 2007 in the area between downtown and the eastern border (Figure 2), leading to increases in both urban areas and bare ground for factory constructions.

Sineuiju is the only top-ten city that lost urban land cover during this time, by $36 \%$ (Table 1). It is quite surprising because Sineuiju has been an important hub of both industry and trade since railroads were built in the early $20^{\text {th }}$ century. It should be noted that a large decrease occurred between the late 1980s and late 1990s, and the change between the late $1990 \mathrm{~s}$ and late 2000s is small. We attribute the large decrease in the former decade to the misclassification of the images in period 1 (1987-1989) based on the observation of old satellite images in Google Earth. The stagnation in the latter decade can be explained by two reasons. First, frequent floods in North Korea, for example the flooding in 1995, affected the urban land cover of Shineuiju (Park \& Yu, 2009). Most of the city area of Shineuiju is lower than the Amnokkang (the Yalu), thus the city is particularly vulnerable to flooding (Dormels, 2014), and North Korea is very resilient to frequent flooding.

Second, Sineuiju's economic development plan has not progressed since 2002 because of changes in on-and-off geopolitical relations between China and North Korea, hindering economic development and expansion of urban areas in Sineuiju (Finch, 2016).

Overall, the urban land cover for the entire country increased from $1405 \mathrm{~km}^{2}$ to $1933 \mathrm{~km}^{2}$ between the 1980s and 2000s (Choi et al., 2017). Even though it increased substantially, urban land cover is still quite small with respect to the entire land area.

\section{Distribution of and Changes in UEII}

The UEII values are quite small in their magnitude, not exceeding 1.3 in any municipality in any time, and generally larger and more variable for the decade between the late 1980s and 1990s than the one between the late 1990s and 2000s (Table 1). For the late 1990s- 
2000s, both the mean and the median are negative, although almost zero, and the range is less than half that of the late 1980s-1990s. The maximum is just about $1 / 4$ of that of the late 1980s-1990s. In short, the result suggests that urban expansion was less intense in the latter period on average, and it is in part because the absolute area of developed lands decreased between the late 1990s and 2000s (Choi et al., 2017). Developed lands for the entire country increased by $44 \%$ during the first decade but decreased by $5 \%$ during the second decade, which could be in part due to classification errors of the remote sensing data and in part due to abandonment of developed lands (Choi et al., 2017).

UEII between the late 1980s data and the late 1990s data is high in some coastal municipalities and in the southwest whereas generally low in most of other parts of the country (Figure 3(a)). During this period, 166 out of 196 municipalities had positive UEII values. Municipalities in and around Pyongyang show high UEII values, suggesting intense urban expansion in and around the nation's capital. The low-lying west coast municipalities also show generally high UEII values, whereas the high-plateau inland region has low UEII values. We note that municipalities with high UEII values generally correspond with the ten largest cities in the latest census (Figure 1). However, often higher UEII values are found just outside the largest cities such as Sineuiju, Gaeseong, Gaecheon, and Dancheon. At the same time, Sineuiju itself and some municipalities inside Pyongyang had negative UEII values.

Between the late 1990s and late 2000s, UEII was larger than zero in 65 out of 196 municipalities, much fewer than the previous decade. Such municipalities are found in and around a few large cities in the west and east such as Pyongyang, Nampo, and Hamheung (Figure 3(b)). Nampo is a port city that connects Pyongyang and the world, and the Pyongyang-Nampo corridor is home to several heavy industry companies (Dormels, 2014). Nampo is well equipped with roads and railroads, and has been handling most of freight that comes to North Korea as humanitarian aid since the 1990s (North Korea Information Portal b). Four contiguous municipalities on the west coast between Sineuiju and Gaecheon show increased UEII, and one of them is Guseong, the $17^{\text {th }}$ largest city by population in the latest census. Guseong continued to grow in population since 1940 (Jo, 2013), which likely resulted in urban expansion. Compared to the previous decade, urban expansion slowed or reversed in the southwestern region and much of the east coast.

The overall stagnation of urban expansion during the late 1990s-2000s may be understood in the political and economic context. The second half of the 1990s was quite a challenging time for North Korea. Kim Il-sung, the country's leader since its foundation, died in 1994, and his son Kim Jong-il inherited the power. But Kim Jong-il did not expose himself to the world until 1997 when he officially became the Chairperson of the Workers' Party, which has been the country's one and only ruling party. In the meantime, North Korea endured so-called Arduous March, which refers to the massive famine during the late 1990s and the political slogan to overcome the famine (MeyerRochow, 2013; Hastings, 2016). The famine had several causes such as the collapse of the Soviet bloc, ineffective and mismanaged economy, and severe natural disasters, and is believed to have led to deforestation during the late 1990s and the 2000s (Kang \& Choi, 
2014). We propose that the long-lasting economic hardship certainly impacted urban land cover changes and land degradation. Moreover, the North Korean government is not very capable of mitigating environmental and land degradations from natural disasters and poorly-managed economy.

\section{Local Spatial Autocorrelation of UEII}

Spatial autocorrelation at the municipal level indicates that there is a strong positive spatial autocorrelation in or around Pyongyang, Gaeseong and Cheongjin $(p<0.01)$ between the late 1980s and 1990s. Such municipalities are marked HH in Figure 4a. In such locations, high UEII values are surrounded by other high UEII values, suggesting clustering of similarly high UEII values. In other parts of the country, no significant spatial autocorrelation is found. Figure 4(a) suggests that urban expansion during the time mostly occurred in the four clusters whereas more or less randomly across space in other regions. Although the most rural municipalities are similar in their characteristics, no significant of spatial autocorrelation of UEII means that there are development in the areas but the patterns are more or less random.

Municipal-level spatial autocorrelation is quite different during the late 1990s-2000s. In particular, municipalities between Gaeseong and Sariweon turned from HH to LL ( $p<$ 0.05 ). When it comes to urban expansion, the southwestern border region underwent a substantial change from expansion to reduction. Such a change in several contiguous municipalities is difficult to explain, but we speculate that some government actions are involved. Gaeseong's population fluctuated widely since 1940 , which is believed to be due to redistricting (Jo, 2013). The provinces between Gaeseong and Pyongyang had negative net migration since 2000 whereas Pyongyang had the largest positive net migration in the country (Ma \& Zeng, 2015). However, we could not find more convincing reason for the urban reduction in the region. On the other hand, some municipalities in or near Pyongyang show positive spatial autocorrelation $(p<0.05)$. A municipality in Pyongyang is marked $\mathrm{HL}$ and another is marked LH, indicating very dissimilar UEII with their neighbors.

\section{Concluding remarks}

This study aimed to help understand the urban expansion in North Korea since the 1980s using satellite-remote-sensing-based land cover datasets. The analysis was conducted at the municipality level as well as for major cities. Previous studies regarding North Korea's urbanization or spatial structure relied on sporadic census data and lacked spatial aspects. Major findings from the study are summarized as follows: (1) Pyongyang's dominance continued without an obvious sign of slowing down; (2) economic development districts do not appear to have much influence on urban land cover changes; (3) the extent of urban land cover slightly decreased in much of the country between the 1990s and 2000s. 
332 The results from the analysis illustrate the phenomena of urban expansion in North Korea 333 in terms of spatial distribution and pace. Considering the lack of reliable data on North

334 Korea, the contribution of this study is meaningful. We propose that North Korea's socio335 economic condition is heavily influenced by geopolitical relations with other countries 336 and was conducive to environmental and land degradation in North Korea. However, we 337 admit that the underlying causes of such phenomena are difficult to find. Nevertheless, 338 the results and discussion presented in the previous section suggest migration and 339 stagnant economy as probably important causes for the phenomena. It is certainly 340 plausible that outmigration left existing urban land cover abandoned (and subsequently 341 converted to something else) whereas migration to Pyongyang led to continued urban 342 expansion. At the same time, natural disasters and the geopolitical relations with 343 neighboring countries in the 1990s likely led to the economic contraction or stagnation in 344 the late 1990s and early 2000s, resulting in the stagnant urban expansion found in this 345 study. 


\section{Reference}

Anselin L. 1995. Local Indicators of Spatial Association - LISA. Geographical Analysis 27(2):93-115

Choi W, Kang S, Choi J, Larsen JJ, Oh C, Na Y. 2017. Characteristics of deforestation in the Democratic People's Republic of Korea (North Korea) between the 1980s and 2000s. Regional Environmental Change 17(2):379-388. DOI: 10.1007/s10113016-1022-3

Dormels R. 2014. Profiles of the cities of DPR Korea - Nampho. In: Anonymous North Korea's Cities. Jimoondang: Seoul

Engler R, Teplyakov V, Adams J. 2014. An Assessment of Forest Cover Trends in South and North Korea, From 1980 to 2010. Environmental Management 53(1):194201. DOI: $10.1007 / \mathrm{s} 00267-013-0201-\mathrm{y}$

Finch S. 2016. Unfinished bridge reveals broken state of North Korea's alliance with China, The Guardian. Retrieved from https://www.theguardian.com/cities/2016/nov/14/dandong-sinuiju-unfinishedbridge-reveals-broken-state-north-korea-alliance-china

Hastings JV. 2016. A Most Enterprising Country: North Korea in the Global Economy. Cornell University Press: Ithaca, the US.

Hwang H, Song S, Jo J. 2011. Comparative analysis of urban interactions on urban spatial expansion and fractal phenomena: Focused on Seoul, Seongnam, Bucheon, Anyang. Journal of Korea Planning Association 46(7):115-133

Jo JC, Adler S. 2002. North Korean planning: Urban changes and regional balance. Cities 19(3):205-215

Jo N. 2013. Trends and characteristics of urbanization in North Korea. KDI Review of the North Korean Economy 15(5):39-60

Jo J, Adler S. 2002. Planning in the socialist developing country: the case of North Korea. Habitat International 26(2):251-267. DOI: 10.1016/S0197-3975(01)00047-9

Kang S. 2016. The empirical analysis for the relationship between flooded buildings and developed area types. Journal of Korean Society of Hazard Mitigation 17(1):349354

Kang S, Choi W. 2014. Forest cover changes in North Korea since the 1980s. Regional Environmental Change 14(1):347-354. DOI: 10.1007/s10113-013-0497-4

Lee H. 2015. Rajin Seonbong Free Economy and Trade District. In: Encyclopedia of Korean Culture. Academy of Korean Studies. Available at http://encykorea.aks.ac.kr/Contents/Index?contents id=E0011520

Lee S. 2011. Analysis on 2008 Census of North Korea and Problems. Policy Research Series 2011-11:1-133

Lim H. 2009. A study on the spatial structure formation and change prospects in North Korea: Focused on North Korea's internal factor and relation with GyeonggiProvince after unification of South and North Korea. GRI Review 11(3):85-112

Lu S, Guan X, He C, Zhang J. 2014. Spatio-Temporal Patterns and Policy Implications of Urban Land Expansion in Metropolitan Areas: A Case Study of Wuhan Urban Agglomeration, Central China. Sustainability 6(8):4723-4748. DOI: $10.3390 /$ su6084723 
Ma Z, Zeng D. 2015. Population and internal migration in North Korea since 2000. Eurasian Geography and Economics 56(4):446-468. DOI: 10.1080/15387216.2015.1103659

Meyer-Rochow, V., 2013, Ethno-entomological observations from North Korea (officially known as the "Democratic People's Republic of Korea"). Journal of Ethnobiology and Ethnomedicine 9(1):7, 1-8

Ministry of Environment. 2013. Guideline on land cover mapping. Ministry of Environment Directive no. 1036. https://egis.me.go.kr/bbs/landcover.do, Last accessed on 2019/4/24

Ministry of Environment. 2016. Overview of the current status of the land cover map, environmental spatial information service. Retrieved from https://egis.me.go.kr/intro/land.do. last accessed on 2019/5/14

North Korea Information Portal. a. Changes in Economic Policy and Outlook for Reform and Opening for North Korea. Available at http://nkinfo.unikorea.go.kr/nkp/overview/nkOverview.do?sumryMenuId=EC204 Last accessed on 2018/1/10

North Korea Information Portal. b. SOC. Available at http://nkinfo.unikorea.go.kr/nkp/overview/nkOverview.do?sumryMenuId=EC210 Last accessed on 2018/1/10

O’Sullivan D, Unwin D. 2010. Geographic Information Analysis. 2nd ed. John Wiley \& Sons. pp. 432

Park C, Yu J. 2009. A Survey of Deforestation in North Korea using Remote Sensing. Journal of Environment Studies 48: 3-24. (in Korean)

Statistics Korea. 1995. Socio-Economic Comparison between the Koreas. The Kookchung Shinmun 355 (available at http://www.korea.kr/ebook/gov/pdf/1995/19951204.pdf)

Statistics Korea. 2011. Press Release. Available at http://kostat.go.kr/portal/korea/kor_nw/2/1/index.board?bmode=read\&aSeq=2460 68 Last accessed on 2018/1/10

Zheng D, Wallin D, Hao Z. 1997. Rates and patterns of landscape change between 1972 and 1988 in the Changbai Mountain area of China and North Korea. Landscape Ecology 12(4):241-254. DOI: 10.1023/A:1007963324520 
Legend

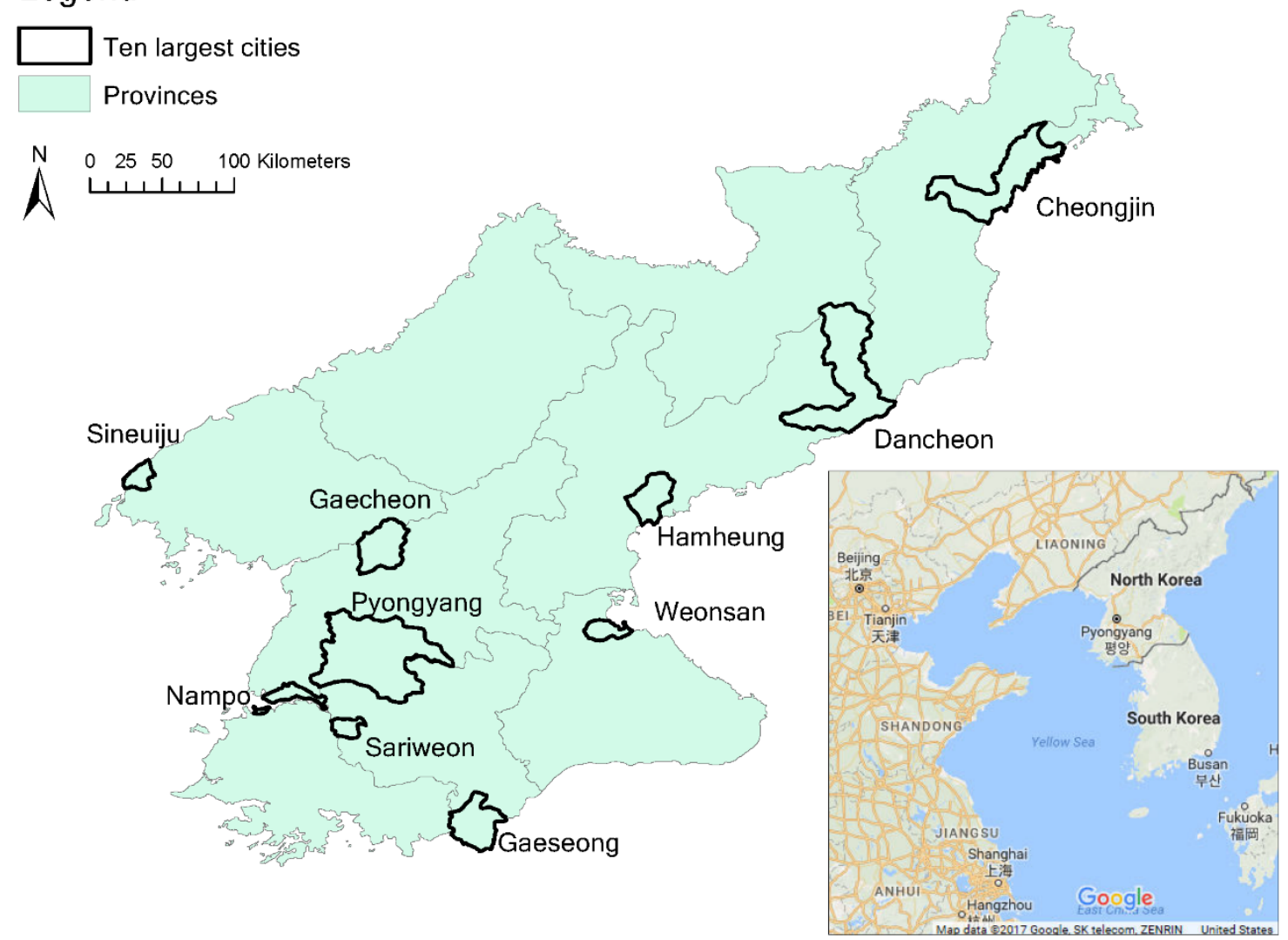

429 Figure 1. Boundaries of provinces and ten largest cities by population of North Korea 430 according to the 2008 Census data 

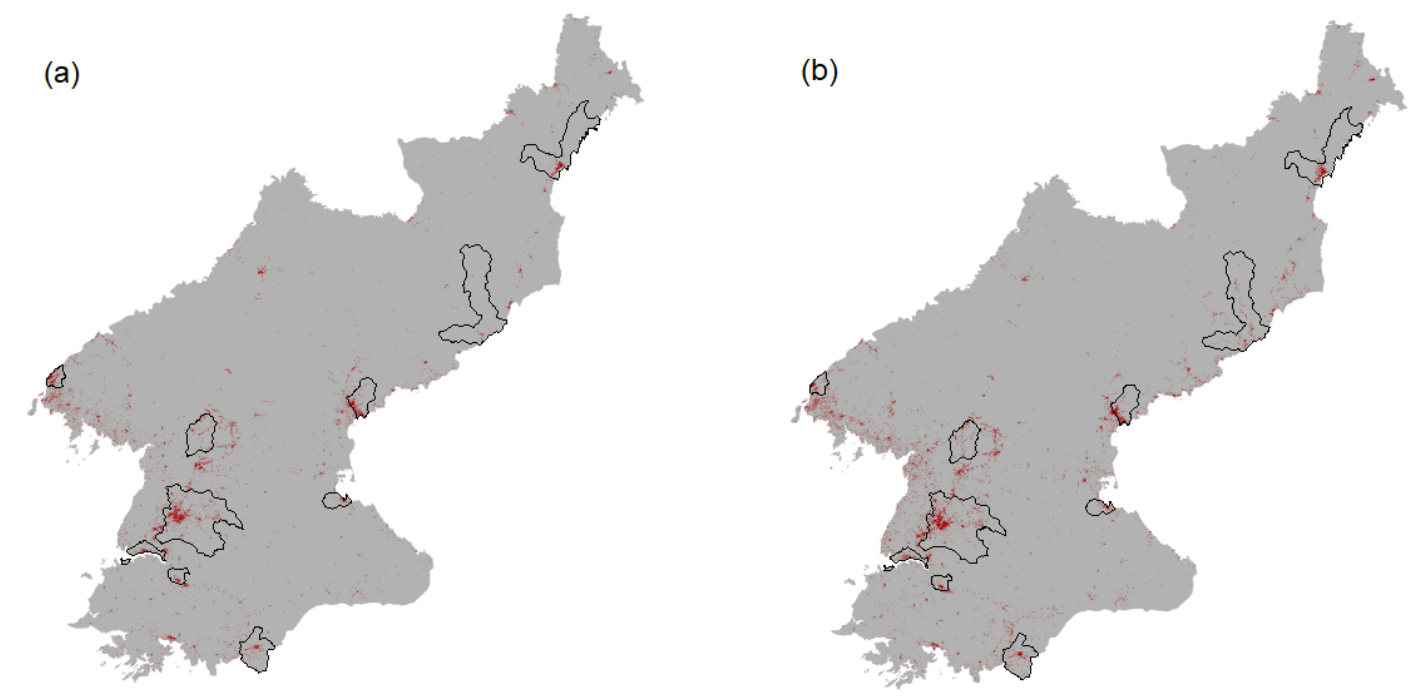

433 Figure 2. Urban pixels (shown in the black polygons) selected from the late 1980s to late 4342000 s for ten cities in North Korea

435 


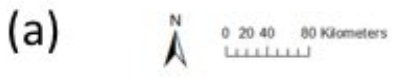

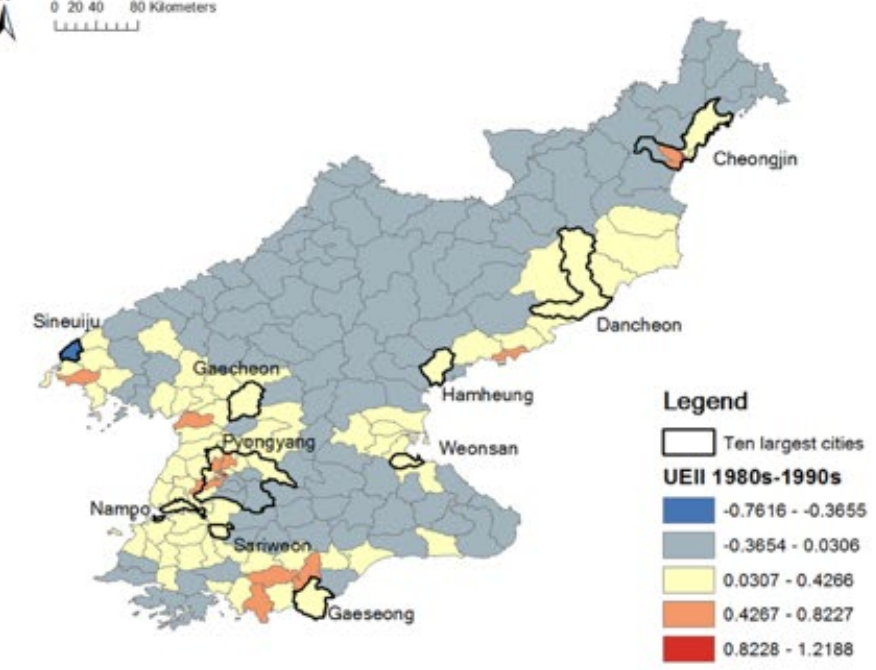

(b)

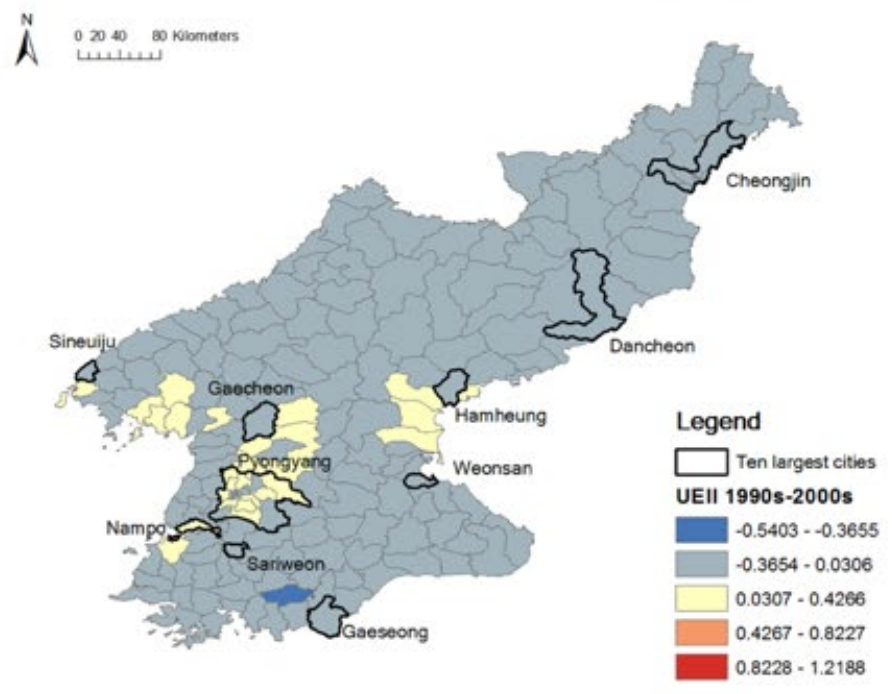

437 Figure 3. UEII for the late 1980s-1990s (a) and the late 1990s-2000s (b) with equal 438 interval classification

439 

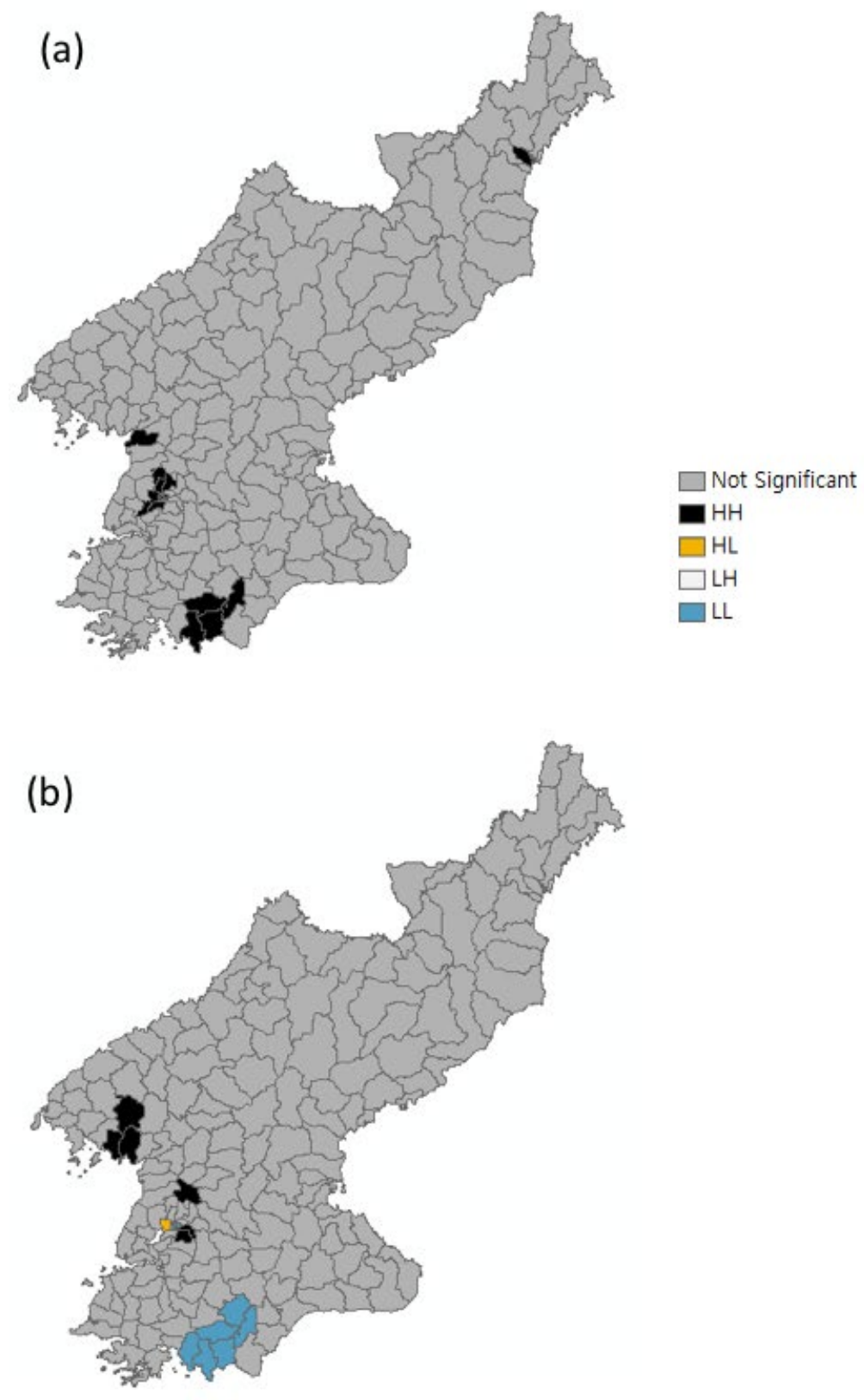

441 Figure 4. Local Moran's I based on UEII for the 1980s-1990s (a) and the late 1990s442 2000s (b) with designations of HH (High-High), HL (High-Low), LH (Low-High), and 443 LL (Low-Low) 
Table 1. Areal extent $\left(\mathrm{km}^{2}\right)$ of urban areas in the ten largest cities in North Korea for the 1980 s and 2000s calculated from the land cover data

\begin{tabular}{|l|r|r|r|}
\hline City & $1980 \mathrm{~s}$ & \multicolumn{2}{|l|}{ Change } \\
\hline Pyongyang & 179.5 & 228.5 & $27.3 \%$ \\
\hline Hamheung & 54.9 & 62.2 & $13.4 \%$ \\
\hline Cheongjin & 39.5 & 58.6 & $48.1 \%$ \\
\hline Nampo & 20.6 & 25.1 & $21.9 \%$ \\
\hline Weonsan & 12.2 & 16.1 & $32.0 \%$ \\
\hline Sineuiju & 41.1 & 26.0 & $-36.8 \%$ \\
\hline Dancheon & 9.3 & 42.2 & $355.8 \%$ \\
\hline Gaecheon & 29.1 & 32.0 & $9.9 \%$ \\
\hline Gaeseong & 30.5 & 47.8 & $56.6 \%$ \\
\hline Sariweon & 14.0 & 14.9 & $6.5 \%$ \\
\hline
\end{tabular}

448

449

450

451

452

453
0.111

0.029

0.224

1.980

$-0.762$

1.219 1990s-2000s

\begin{tabular}{lc}
\hline \multicolumn{2}{c}{ 1990s-2000s } \\
\hline Mean & -0.008 \\
Median & -0.004 \\
Standard deviation & 0.093 \\
Range & 0.878 \\
Minimum & -0.540 \\
Maximum & 0.338 \\
\hline
\end{tabular}

